Article

\title{
The Effect of Increasing Sn Content on High-Temperature Mechanical Deformation of an $\mathrm{Mg}-3 \% \mathrm{Cu}-1 \% \mathrm{Ca}$ Alloy
}

\section{Georgios S.E. Antipas}

School of Mining Engineering and Metallurgy, National Technical University of Athens, Zografou Campus, Athens 15780, Greece; E-Mail: gantipas@metal.ntua.gr; Tel.: +30-210-7722037

Received: 14 September 2013; in revised form: 27 October 2013 / Accepted: 28 October 2013 / Published: 1 November 2013

\begin{abstract}
Chill casting of magnesium alloy samples with secondary alloying elements of $\mathrm{Cu}, \mathrm{Ca}$ and $\mathrm{Sn}$ at \% w.t. concentrations in the range $1-5,0.1-5$ and $0.1-3$ respectively, gave rise to appreciably enhanced resistance to high-temperature creep, while maintaining good heat conductivity. The latter was considered to be driven by $\mathrm{Cu}$ and $\mathrm{Mg}-\mathrm{Cu}$ intermetallics while it was clear that $\mathrm{Sn}$ mediated the high-temperature performance, mainly via networks of $\mathrm{Mg}_{2} \mathrm{Sn}$ and $\mathrm{MgCaSn}$ precipitates along the $\mathrm{Mg}$ matrix grain boundaries. It was postulated that Sn formed intermetallics by preferential substitution of $\mathrm{Ca}$ atoms and, thus, did not degrade the heat conductivity by retaining $\mathrm{Cu}$. The \% w.t. stoichiometry with the optimum combination of heat conductivity and resistance to high-temperature creep was found to be $\mathrm{Mg}-3 \mathrm{Cu}-1 \mathrm{Ca}-0.1 \mathrm{Sn}$.
\end{abstract}

Keywords: Mg alloys; heat conductivity; creep resistance; tin addition; $\mathrm{Mg}-\mathrm{Cu}-\mathrm{Ca}-\mathrm{Sn}$

\section{Introduction}

Spanning the spectrum of aeronautics and the space sector, to the more down to earth automobile industry [1,2] and the engineering/construction sector, magnesium and its light alloys are in direct competition with Al-based alloys and their associated light-element solubility-extension techniques [3-8] and underpin any structural choice that calls for low density and fair heat dissipation $[1,2]$. Lately, magnesium has also become a symbol of sustainable economic development, drawing attention as an element of preference towards the reduction of greenhouse gas emissions [1]. Along with their advantages, two major drawbacks are also associated with magnesium alloys: (a) their problematic formability at ambient conditions, due to localized slip and stresses building up along grain boundaries 
upon mechanical deformation [9], and (b) their invariable failure in high-temperature applications [10]. A typical example of the latter is the ASTM AZ91D magnesium alloy with a heat conductivity of approximately $73 \mathrm{~W} / \mathrm{mK}$ [11]; when used in high temperature components heat dissipation is frequently inefficient, resulting in the component's thermal deformation. Correspondingly, part of the ongoing research is related to $\mathrm{Mg}$ alloy stoichiometries that will maximize the material's performance at high temperatures. As a first step, the addition of $\mathrm{Ca}$, in replacement of the costly rare earth metals [12], is known to increase $\mathrm{Mg}$ alloy ductility through grain size refinement in quantities of up to $0.3 \%$ [13]. Ca also improves creep resistance, attributed to the thermal stability and the interface coherency between the $\mathrm{Mg}_{2} \mathrm{Ca}$ precipitates and the $\mathrm{Mg}$ matrix [14]. The resulting $\mathrm{Mg}-\mathrm{Ca}$ alloys show lower secondary creep rates and higher tensile strength than, e.g., the AZ91 alloy; these Mg-Ca alloy benefits are also coupled with improved castability and good melt handling [10,13]. Combined with secondary inclusions of $\mathrm{Cu}$, the $\mathrm{Mg}-\mathrm{Ca}$ system is a good example of alloy property tuning, outperforming the heat dissipation of the AZ91D alloy, largely due to its $\mathrm{Cu}$ content; however this improvement in high temperature performance comes at the price of reduced alloy corrosion, owing to precipitation of $\mathrm{Mg}_{2} \mathrm{Ca}$ intermetallics $[9,15]$.

It could be argued that further alloying element modifications might benefit $\mathrm{Mg}$ alloy creep resistance at high temperatures, while preserving enhancements of heat conductivity. Tin has been known as such an alloying element, forming $\mathrm{Mg}$-Sn intermetallic networks by mainly assuming $\mathrm{Ca}$ sites by substitution; these networks have been reported to block grain-boundary sliding, particularly at high temperatures [16]. Hence, in the current work, the case is made for a $\mathrm{Mg}-\mathrm{Cu}-\mathrm{Ca}-\mathrm{Sn}$ stoichiometry in which $\mathrm{Sn}$ substitutes $\mathrm{Ca}$ preferentially, while the alloy maintains a functional level of heat conductivity promoted by $\mathrm{Cu}$; the proposed alloy is intended for high-temperature mechanical deformation and the synthesis route is proposed to be either gravity, pressure, or indeed chill casting, in a variety of moulds. Most importantly, however, no particular restrictions are set to the synthesis route's solidification rate, as $\mathrm{Mg}$-Sn networks have shown to form even at ambient cooling conditions.

\section{Materials and Methods}

Magnesium alloy samples were prepared by direct chill casting in five different runs that produced test samples of varying stoichiometries, in furnace ambient conditions. The elemental concentrations used varied in the ranges $1 \%$ w.t. $-5 \%$ w.t. for $\mathrm{Cu}, 0.1 \%$ w.t. $-5 \%$ w.t. for $\mathrm{Ca}$ and $0.1 \%$ w.t. $-3 \%$ w.t. for Sn. In every run, an iron crucible was preheated to $500{ }^{\circ} \mathrm{C}$ in an electric furnace and its inner surface was coated by a chloride flux. The desired quantities of pure $(\sim 99.998 \%) \mathrm{Mg}, \mathrm{Cu}, \mathrm{Ca}$ and $\mathrm{Sn}$ elements were then deposited in the crucible and brought to $750{ }^{\circ} \mathrm{C}$. The melt was then stirred every half an hour for two hours and was left to rest for another four hours before being poured into a metallic mould with dimensions $30 \times 30 \times 200 \mathrm{~mm}$. The ingots were then left to solidify at ambient conditions. The heat conductivities of the as-cast samples as well as of AZ91D alloy samples were determined by a transient laser flash method [17]. Alloy creep resistance was examined via stress relaxation tests; for each sample, the stress decrease in respect with time was recorded up to a predetermined deformation, for an initial applied load of $100 \mathrm{MPa}$, while each sample was kept at $200{ }^{\circ} \mathrm{C}$ in atmospheric pressure. The applied load was then reduced gradually so as to keep the rate of displacement constant for each sample. X-ray diffraction (XRD) spectra were recorded on a Bruker D8-Focus diffractometer with 
nickel-filtered $\mathrm{Cu} \mathrm{K \alpha}$ radiation $(\lambda=1.5405 \AA), 40 \mathrm{kV}$ and $40 \mathrm{~mA}$. Sample cross sections were examined by scanning electron microscopy (SEM) on a Jeol 6380LV SEM.

\section{Results and Discussion}

Of the samples cast, only alloying compositions of $3 \%$ w.t. in $\mathrm{Cu}$ and $1 \%$ w.t. in $\mathrm{Ca}$ were found to be of engineering interest, yielding improved heat conductivity and creep resistance compared to the AZ91D reference alloy; hence only these stoichiometries will be the focus of the forthcoming discussion. For the remainder of the samples, generic comments will be made here. As indexed by energy-dispersive X-ray spectroscopy (EDS), alloy $\mathrm{Cu}$ concentrations in the order of $1 \%$ w.t. resulted in the precipitation of the $\mathrm{CuMg}_{2}$ intermetallic, mostly along grain boundaries. The concentration of these intermetallics was found to decrease with decreasing $\mathrm{Cu}$ content. Also, for Ca content roughly exceeding $5 \%$ w.t., a reduction in the material's tensile strength and elongation prior to fracture was observed. The correlation between alloy mechanical properties and the alloying element content farther away from the apparent optimal $3 \%$ w.t in $\mathrm{Cu}$ and $1 \%$ w.t. in $\mathrm{Ca}$ was unclear and could not be drawn.

The chemical compositions of samples with engineering interest are listed in Table 1. In Sample S1 networks of the low-strength intermetallic $\mathrm{CuMg}_{2}$ [18] and high-strength high-temperature $\mathrm{Mg}_{2} \mathrm{Ca}$ [19] phases (as indexed by XRD) were observed along grain boundaries. Addition of Sn in increasing amounts was observed to mediate formation of finer (and seemingly more continuous) intermetallic $\mathrm{CuMg}_{2}$ and $\mathrm{Mg}_{2} \mathrm{Ca}$ phases, as revealed by a comparison of Samples S2 and S3 with S1. Additionally, formation of the MgCaSn phase was also indexed in Samples S2 and S3. In the case of Sn-rich Samples, S4 and S5, the presence of the MgCaSn networks was again confirmed, albeit formed incompletely and appearing even within grains; particular to Sample S5, the low-melting-point $\mathrm{Mg}_{2} \mathrm{Sn}$ compound was also indexed as present.

Table 1. Heat conductivities and stress decrease magnitudes for all samples tested.

\begin{tabular}{cccc}
\hline Sample index & Composition (\% w.t.) & Heat conductivity (W/mK) & Load decrease (MPa) \\
\hline S1 & $\mathrm{Mg} 3 \% \mathrm{Cu} 1 \% \mathrm{Ca}$ & 155 & 65 \\
$\mathrm{~S} 2$ & $\mathrm{Mg} 3 \% \mathrm{Cu} 1 \% \mathrm{Ca} 0.1 \% \mathrm{Sn}$ & 163 & 54 \\
$\mathrm{~S} 3$ & $\mathrm{Mg} 3 \% \mathrm{Cu} 1 \% \mathrm{Ca} 1 \% \mathrm{Sn}$ & 154 & 52 \\
$\mathrm{~S} 4$ & $\mathrm{Mg} 3 \% \mathrm{Cu} 1 \% \mathrm{Ca} 2 \% \mathrm{Sn}$ & 148 & 59 \\
$\mathrm{~S} 5$ & $\mathrm{Mg} 3 \% \mathrm{Cu} 1 \% \mathrm{Ca} 4 \% \mathrm{Sn}$ & 122 & 67 \\
$\mathrm{AZ} 91 \mathrm{D}$ & $\mathrm{Mg} \% \% \mathrm{~A} 11 \% \mathrm{Zn}$ & 73 & 60 \\
\hline
\end{tabular}

Heat conductivity and load decrease magnitude measurements are presented in Figure 1. As an introductory comment, the heat conductivity of reference Sample S1 (void of Sn additions) was appreciably high, at a value of $150 \mathrm{~W} / \mathrm{mK}$. All of Samples S2 through to S5 exhibited superior (higher) heat conductivities in comparison to that of the commercial AZ91D alloy as well as compared to S1. Altogether, Sn addition to Samples S2 to S4 was not found to cause appreciable differences to their heat conductivity (again, as compared to reference Sample S1). However, in the case of Sn-rich Sample S5, a marked reduction in heat conductivity was observed but the sample still dissipated heat 
more effectively than the AZ91D alloy. The latter observation could, potentially, flag an Sn composition maximum for enhanced conductivity behavior.

Figure 1. Heat conductivity and load decrease measurements. The sample index relates to Table 1 .

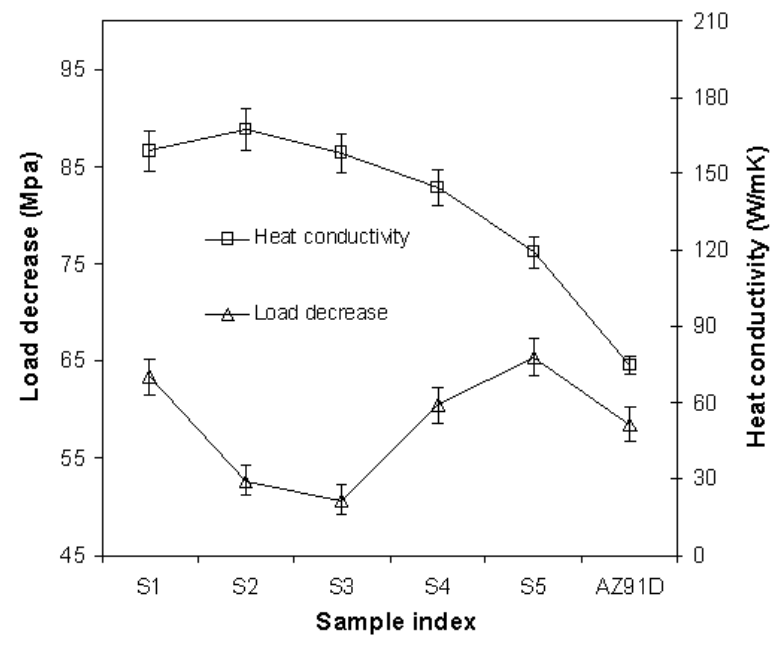

The stress decrease rate, shown in Figure 2, reached a plateau at the value for Sample S3; hence the $1 \%$ w.t. Sn content appears to offer optimal mechanical resistance to creep out of the stoichiometries tested in this work. This improvement in creep resistance may be explained by the existence of networks of $\mathrm{CuMg}_{2}$ intermetallics that form along grain boundaries [16]; in contrast, metallographic observations from the S1 sample revealed less frequent occurrences of this phase, however these observations were purely qualitative. In the case of Samples S2 through to S4, the stress decrease rate was more acute in the initial $3 \mathrm{~h}$-period of the test, while during the remainder of the experiment this rate was essentially negligible. Sample S5 exhibited the lowest creep resistance, attributed to the alloy's $\mathrm{Sn}$ content of $4 \%$ w.t., the precipitate networks of which were observed to include the $\mathrm{Mg}_{2} \mathrm{Sn}$ intermetallic.

Figure 2. Stress versus time for a period of up to $40 \mathrm{~h}$ from the onset of the experiment.

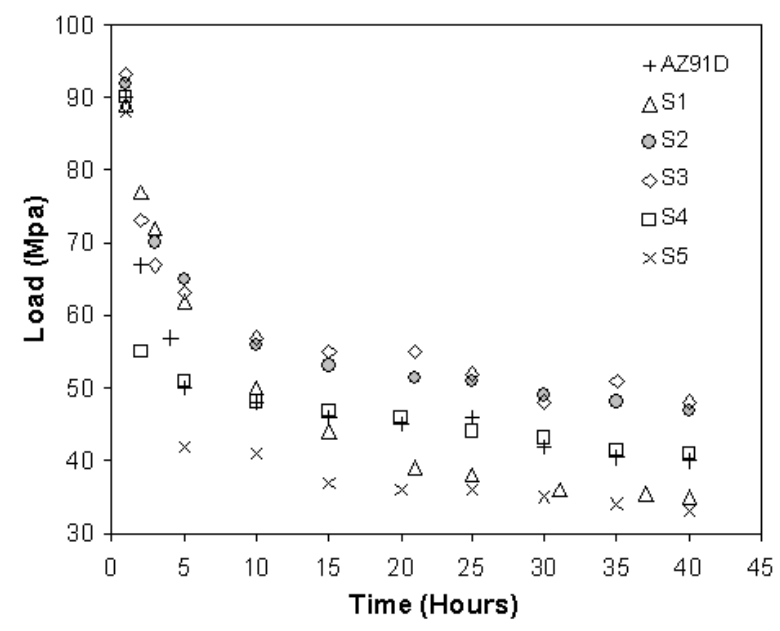

For Sn concentrations higher than $0.1 \%$ w.t., the $\mathrm{MgCaSn}$ phase [20] was observed to precipitate along grain boundaries, in conjunction with the $\mathrm{CuMg}_{2}$ phase, forming intermetallic networks. For 
higher $\mathrm{Sn}$ content (the precise limit was unresolved but certainly higher than $2 \%$ w.t.), precipitation of $\mathrm{MgCaSn}$ intermetallics was observed within the grains and it was considered that they contributed less to localized slip control which, in turn, caused a reduction in creep resistance. Sn compositions as high as $3 \%$ w.t. caused the a joint precipitate of the low melting-point $\mathrm{Mg}_{2} \mathrm{Sn}$ intermetallic in addition to the $\mathrm{MgCaSn}$ phase, causing an even further reduction $\mathrm{n}$ of the material's creep resistance. To generalize, precipitation of Sn-rich intermetallics was largely found to be a consequence of the competitive contributions by $\mathrm{Sn}$ and $\mathrm{Ca}$; for $\mathrm{Sn} / \mathrm{Ca}$ ratios below 3, formation of low melting-point intermetallics was generally suppressed, while for $\mathrm{Sn} / \mathrm{Ca}$ ratios below 2, intermetallic networks were formed that improved high-temperature strength and creep resistance. Sn additions did not measurably affect the increased heat conductivity mediated by $\mathrm{CuMg}_{2}$ intermetallics, an observation that is probably underpinned by the thermodynamic preference of $\mathrm{Sn}$ to substitute $\mathrm{Ca}$ rather than $\mathrm{Mg}$ or $\mathrm{Cu}$ elements [20]. Along these lines, an appropriate concentration for $\mathrm{Sn}$ in the $\mathrm{Mg}-3 \% \mathrm{Cu}-1 \% \mathrm{Ca}$ system appears to be in the range $0.1 \%$ w.t. $-2 \%$ w.t.

\section{Conclusions}

Based on selected chill-cast $\mathrm{Mg}$ alloys, secondary inclusions of $\mathrm{Ca}$ and $\mathrm{Sn}$ formed intermetallics that precipitated in networks along grain boundaries and appeared to suppress grain-boundary slip at $200{ }^{\circ} \mathrm{C}$. Furthermore, $\mathrm{Cu}$ elemental additions responsible for the alloy's good heat dissipation were not affected, as Sn was observed to mainly interact with $\mathrm{Ca}$ and $\mathrm{Mg}$.

\section{Conflicts of Interest}

The author declares no conflict of interest.

\section{References}

1. Guo, K.W. A review of magnesium/magnesium alloys corrosion and its protection. Recent Pat. Corros. Sci. 2010, 2, 13-21.

2. Hakamada, M.; Furuta, T.; Chino, Y.; Chen, Y.; Kusuda, H.; Mabuchi, M. Life cycle inventory study on magnesium alloy substitution in vehicles. Energy 2007, 32, 1352-1360.

3. Antipas, G.S.E. A review of gas atomization and spray forming phenomenology. Powder Metall. 2013, 56, 317-330.

4. Antipas, G.S.E. Spray forming of al alloys: Experiment and theory. Mater. Res. 2012, 15, 131-135.

5. Antipas, G.S.E.; Lekakou, C.; Tsakiropoulos, P. Microstructural characterisation of Al-Hf and Al-Li-Hf spray deposits. Mater. Charact. 2011, 62, 402-408.

6. Antipas, G.S.E. Modelling of the break up mechanism in gas atomization of liquid metals Part II. The gas flow model. Comput. Mater. Sci. 2009, 46, 955-959.

7. Antipas, G.S.E. Modelling of the break up mechanism in gas atomization of liquid metals. Part I: The surface wave formation model. Comput. Mater. Sci. 2006, 35, 416-422.

8. Antipas, G.S.E. Mathematical Modeling of Metal Spray Forming; University of Oxford, Oxford, UK, 1998. 
9. Zhou, D.W.; Liu, J.S.; Peng, P.; Chen, L.; Hu, Y.J. A first-principles study on the structural stability of $\mathrm{Al}_{2} \mathrm{Ca} \mathrm{Al}_{4} \mathrm{Ca}$ and $\mathrm{Mg}_{2} \mathrm{Ca}$ phases. Mater. Lett. 2008, 62, 206-210.

10. Powell, B.R.; Rezhets, V.; Balogh, M.P.; Waldo, R.A. Microstructure and creep behavior in AE42 magnesium die-casting alloy. JOM 2002, 54, 34-38.

11. Xiao, Z.H.; Luo, J.R.; Wu, S.S.; Li, D.N.; Mao, Y.W.; Song, X.J. Study on a semi-solid rheo-diecasting process with AZ91D alloy slurry. J. Mater. Eng. Perform. 2004, 13, 60-63.

12. Aljarrah, M.; Medraj, M.; Wang, X.; Essadiqi, E.; Muntasar, A.; Dénès, G. Experimental investigation of the MgAlCa system. J. Alloys Compd. 2007, 436, 131-141.

13. Pekguleryuz, M.O.; Baril, E. Creep resistant magnesium diecasting alloys based on alkaline earth elements. Mater. Trans. 2001, 42, 1258-1267.

14. Bakhsheshi-Rad, H.R.; Idris, M.H.; Kadir, M.R.A.; Farahany, S.; Lotfabadi, A.F.; Suhasril, A.A. Effect of secondary phase on the corrosion behavior of $\mathrm{Mg}-\mathrm{Ca}$ and $\mathrm{Mg}-\mathrm{Zn}$ binary alloys. Adv. Sci. Lett. 2013, 19, 2553-2557.

15. Salahshoor, M.; Guo, Y. Biodegradable orthopedic magnesium-calcium (MgCa) alloys. Process. Corros. Perform. Mater. 2012, 5, 135-155.

16. Avraham, S.; Katsman, A.; Bamberger, M. Strengthning Mechanisms in MG-AL-SN Based Alloys. In Proceedings of Magnesium International Conference, Haifa, Israel, 15-19 February 2009; pp. 471-475.

17. Zajas, J.; Heiselberg, P. Determination of the local thermal conductivity of functionally graded materials by a laser flash method. Int. J. Heat Mass Transf. 2013, 60, 542-548.

18. Takeuchi, A.; Yubuta, K.; Inoue, A. Phase stability of $\mathrm{Cu} 2 \mathrm{Mg}$ and $\mathrm{CuMg} 2$ compounds against noncrystallizations analyzed with a plastic crystal model. Intermetallics 2008, 16, 1273-1278.

19. Chino, Y.; Kobata, M.; Iwasaki, H.; Mabuchi, M. Tensile properties from room temperature to $673 \mathrm{~K}$ of Mg-0.9 mass \% $\mathrm{Ca}$ alloy containing lamella $\mathrm{Mg}_{2} \mathrm{Ca}$. Mater. Trans. 2002, 43, 2643-2646.

20. Arróyave, R.; Liu, Z.-K. Intermetallics in the Mg-Ca-Sn ternary system: Structural, vibrational, and thermodynamic properties from first principles. Phys. Rev. B 2006, 74, 174118.

(C) 2013 by the authors; licensee MDPI, Basel, Switzerland. This article is an open access article distributed under the terms and conditions of the Creative Commons Attribution license (http://creativecommons.org/licenses/by/3.0/). 